\title{
LABELLING OF SEMEN WITH RADIO-ACTIVE PHOSPHATE
}

\author{
A. TAKEDA, G. LUTWAK-MANN AND T. MANN \\ A.R.C. Unit of Reproductive Physiology and Biochemistry, \\ University of Cambridge
}

\section{(Received 3rd Fanuary 1968)}

The purpose of the preliminary experiments described below was to label mammalian spermatozoa with ${ }^{32} \mathrm{P}$ to such a degree that they could afterwards be used for a quantitative follow-up of the so-called leakage of intracellular sperm compounds, such as is known to accompany sperm 'ageing' or 'senescence' (Mann, 1964). The approach was twofold, by means of labelling in vivo and in vitro.

The in-vivo study, in which four buck rabbits were injected subcutaneously with inorganic $\left[{ }^{32} \mathrm{P}\right]$ phosphate $(1 \mathrm{mc} /$ animal $)$, included radio-activity assays by liquid scintillation counting of urine, blood plasma, blood corpuscles, seminal plasma and spermatozoa. In the urine and blood plasma, specific radio-activity, high at first, declined rapidly, reaching a very low level by the end of the first month. In the blood corpuscles, there was first a decline in radio-activity which, however, during the second half of the month was followed by a characteristic increase, most probably due to the appearance of erythrocytes which had earlier undergone labelling in the bone marrow. In the seminal plasma, as obtained by centrifugation of ejaculated semen, radioactivity fluctuated considerably more than in blood plasma (Text-fig. 1), presumably due partly to differences in time at which various seminal constituents become maximally labelled, but partly also to fluctuations in the contribution of the different accessory secretions towards the make-up of individual ejaculates. In spermatozoa separated from seminal plasma by centrifugation, and washed three times with Ringer solution, radio-activity remained low until 40 to 42 days after the injection of $\left[{ }^{32} \mathrm{P}\right]$ phosphate. From then on it began to rise steeply, as could be expected from the study of Amann, Koefoed-Johnsen \& Levi (1965) who found that an injection of $\left[{ }^{3} \mathrm{H}\right]$ thymidine to rabbits is followed 38 to 42 days later by the appearance of ${ }^{3} \mathrm{H}$-labelled DNA in ejaculated spermatozoa. In our rabbits, however, the total specific radio-activity at any time during the period 40 to 60 days, never exceeded 3000 counts $/ \mathrm{min} / 30 \times 10^{6}$ spermatozoa (equivalent to about $0.2 \mathrm{ml}$ of whole semen). The ${ }^{32}$ P-labelled spermatozoa, when suspended in Ringer solution (at the same sperm concentration as in whole semen) and incubated for $1 \mathrm{hr}$ at $37^{\circ} \mathrm{C}$, released up to $7 \%$ of their ${ }^{32} \mathrm{P}$ into the extracellular medium. This does not, however, rule out the possibility that simple radionucleide interchange reactions may have also contributed to the ${ }^{32} \mathrm{P}$ release. In one experiment, the leakage of ${ }^{32} \mathrm{P}$ from the spermatozoa into saline was compared with 
leakage into uterine fluid, which had been collected from an oestrous rabbit as described by Lutwak-Mann (1962). More radio-active P passed from the labelled spermatozoa into the uterine fluid than into saline. However, since the degree of total labelling in that particular sperm sample was low, this observation will have to be confirmed by using spermatozoa with higher radio-activity.

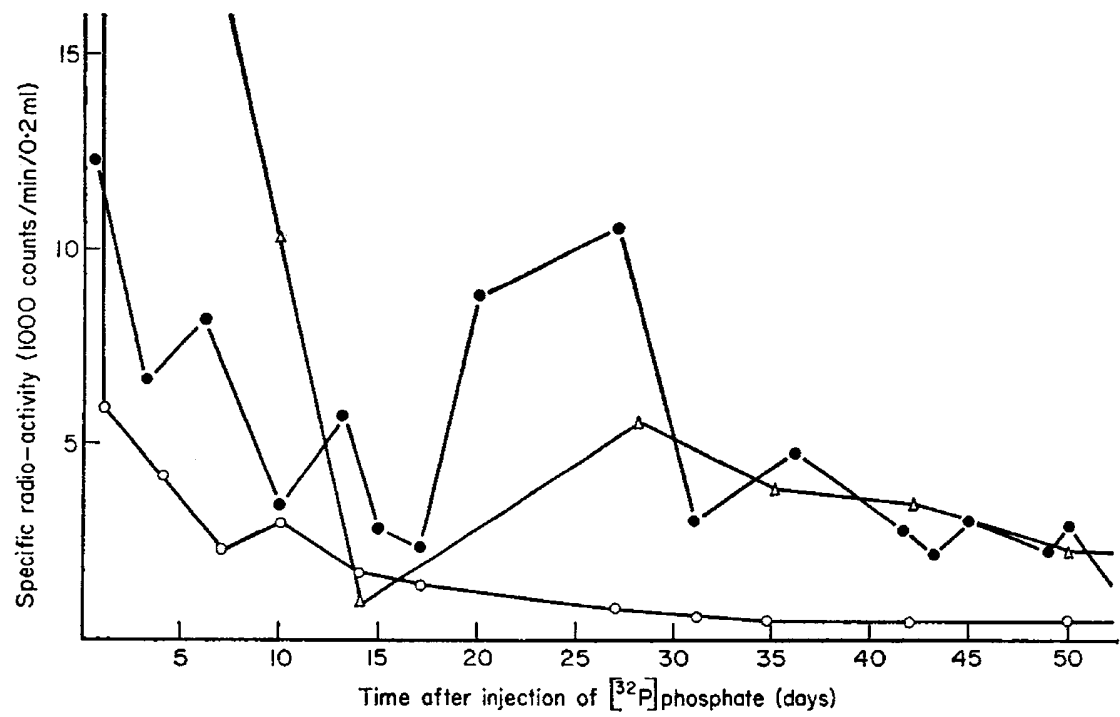

TexT-Fig. 1. Appearance of radio-activity after a single injection of $1 \mathrm{mc}$ of [32P]phosphate to a male rabbit. $O$, Blood plasma, $0.2 \mathrm{ml} ; \Delta$, blood corpuscles from $0.2 \mathrm{ml}$ blood; @, seminal plasma, $0.2 \mathrm{ml}$.

In-vitro labelling of spermatozoa was carried out in two series of experiments with bull semen using 0.7 to $1.2 \mu \mathrm{c}$ of ${ }^{32} \mathrm{P} / \mathrm{ml}$, which is a level of radio-activity much higher than that employed in the early studies of similar kind by Bishop \& Weinstock (1948) and Bishop (1950). In one series of experiments, semen was diluted with an equal volume of ${ }^{32} \mathrm{P}$-containing Ringer solution and kept anaerobically for $1 \mathrm{hr}$ at $37^{\circ} \mathrm{C}$ before centrifugation and washing of spermatozoa. In the other series, the spermatozoa were subjected to ${ }^{32} \mathrm{P}$-treatment after they had been separated by washing from normal semen, and suspended in saline. The level of radio-activity of motile bovine spermatozoa obtained by either of these two methods varied from 7000 to 30,000 counts $/ \mathrm{min} / 10^{8} \mathrm{sperm}$ atozoa. However, similarly high levels were also occasionally observed in spermatozoa which, before incubation, have first been rendered immotile by heating at $55^{\circ} \mathrm{C}$. When in-vitro labelled bovine spermatozoa were fractionated according to Schmidt \& Thannhauser (1945) and Dawson (1958), only up to $70 \%$ of ${ }^{32} \mathrm{P}$ appeared in the 'acid-soluble P-fraction', and the rest was present in other fractions, including the so-called 'DNA' and 'residual' fraction; the true nature of the labelled P-compounds present in these fractions remains to be investigated. The bovine sperm suspensions prepared by labelling in vitro (same sperm concentration as in semen), when incubated at $37^{\circ} \mathrm{C}$ for $2 \mathrm{hr}$, 
released up to $50 \%$ of their ${ }^{32} \mathrm{P}$. At $10^{\circ} \mathrm{C}$ a similar amount was released in $20 \mathrm{hr}$; and at $5^{\circ} \mathrm{C} 18 \%$ and $34 \%$ was released after $21 \mathrm{hr}$ and $48 \mathrm{hr}$, respectively. The release was accompanied by a decrease of radio-activity in all $\mathbf{P}$-fractions obtained by the Schmidt-Thannhauser procedure, and not merely in the 'acidsoluble phosphate'.

We wish to thank Dr J. G. Boursnell, Dr R. M. C. Dawson and Mr R. Harrison for valuable help and suggestions.

\section{REFERENCES}

Amann, R. P., Koefoed-Johnsen, H. H. \& Levi, H. (1965) Excretion pattern of labelled spermatozoa and the timing of spermatozoa formation and epididymal transit in rabbits injected with thymidine- ${ }^{3}$ H. F. Reprod. Fert. $10,169$.

Bishop, D. W. (1950) Anaerobic pickup of $\mathrm{P}^{32}$ by seminal bull sperm. Anat. Rec. 108, 573.

Bishop, D. W. \& Wernstock, I. (1948) Uptake of radioactive phosphorus by bull spermatozoa. Anat. Rec. 101, 731.

DAwson, R. M. C. (1958) The labelling of ram semen in vivo with radioactive phosphate and [carboxy$\left.{ }^{14} \mathrm{C}\right]$ stearic acid. Biochem. F. 68, 512.

Lutwak-ManN, C. (1962) Some properties of uterine and cervical fluid in the rabbit. Biochim. biophys. Acta, 58, 637.

Mann, T. (1964) Biochemistry of semen and of the male reproductive tract. Methuen, London.

Schmidt, G. \& Thannhauser, S. J. (1945) A method for the determination of deoxyribonucleic acid, ribonucleic acid, and phosphoproteins in animal tissues. F. biol. Chem. 161, 83. 